NBER WORKING PAPER SERIES

\title{
EFFECTS OF DAILY SCHOOL AND CARE DISRUPTIONS DURING THE COVID-19 PANDEMIC ON CHILD MENTAL HEALTH
}

\author{
Anna Gassman-Pines \\ Elizabeth Ananat \\ John Fitz-Henley II \\ Jane Leer \\ Working Paper 29659 \\ http://www.nber.org/papers/w29659 \\ NATIONAL BUREAU OF ECONOMIC RESEARCH \\ 1050 Massachusetts Avenue \\ Cambridge, MA 02138 \\ January 2022
}

The authors gratefully acknowledge support from the Eunice Kennedy Shriver National Institute of Child Health and Human Development, National Institutes of Health (\#1R21HD100893-01), the National Science Foundation (\# SES-1921190), the Russell Sage Foundation (\#1811-10382), and the Washington Center for Equitable Growth. Jennifer Copeland provided excellent research support. The views expressed herein are those of the authors and do not necessarily reflect the views of the National Bureau of Economic Research.

NBER working papers are circulated for discussion and comment purposes. They have not been peer-reviewed or been subject to the review by the NBER Board of Directors that accompanies official NBER publications.

(C) 2022 by Anna Gassman-Pines, Elizabeth Ananat, John Fitz-Henley II, and Jane Leer. All rights reserved. Short sections of text, not to exceed two paragraphs, may be quoted without explicit permission provided that full credit, including $\left({ }^{\circ}\right.$ notice, is given to the source. 
Effects of Daily School and Care Disruptions During the COVID-19 Pandemic on Child Mental Health

Anna Gassman-Pines, Elizabeth Ananat, John Fitz-Henley II, and Jane Leer

NBER Working Paper No. 29659

January 2022

JEL No. I0

\begin{abstract}
The COVID-19 pandemic has profoundly affected American children, including disruptions to their care and school settings. Children attending in-person child care or school have contended with unpredictable closures and time in remote school, which in turn is subject to its own types of disruptions (hardware, software, and internet failures). This study investigated the frequency and consequences of disruptions to children's child care and school arrangements during fall 2020. The study includes a representative sample of hourly service-sector workers parents of a young child from a major U.S. city $(\mathrm{N}=679)$; half are non-Hispanic Black, $23 \%$ are Hispanic; $18 \%$ are non-Hispanic White. Parents were asked to complete 30 days of daily surveys about whether their care and school arrangements went smoothly and as predicted that day, and about their mood, parenting behaviors, and children's behavior. Results showed that daily disruptions to care and school were common, with families reporting a disruption on $24 \%$ of days. Families with children in remote schooling experienced more frequent disruption than families with children in inperson care or school. For all families, care or school disruptions strongly predicted worse child behavior, more negative parental mood, and increased likelihood of losing temper and punishment.

Anna Gassman-Pines

Sanford School of Public Policy

Duke University

Box 90245

Durham, NC 27708

agassman.pines@duke.edu

Elizabeth Ananat

Barnard College

Columbia University

3009 Broadway

Office 1019 Milstein Building

New York, NY 10027

and NBER

eananat@barnard.edu

John Fitz-Henley II

Sanford School of Public Policy

Duke University

Durham, NC 27510

john.fitz.henley@duke.edu

Jane Leer

Sanford School of Public Policy

Duke University

Durham, NC 27510

jane.leer@duke.edu
\end{abstract}


The outbreak of the novel coronavirus has profoundly affected American families. Most areas of the country have experienced stay-at-home orders (National Academy for State Health Policy, 2020), unemployment claims skyrocketed to unprecedented levels (Bureau of Labor Statistics, 2020), and millions of cases of the illness have been confirmed (Center for Systems Science and Engineering at Johns Hopkins University, 2020). Given the size and scope of both the economic and health effects of the current crisis, it likely has strongly affected the psychological well-being of both parents and children (Gassman-Pines et al., 2020), but there continues to be limited evidence about psychological effects.

One substantial change for many children during the COVID-19 crisis has been the closure or change in the nature of their primary care and school settings. At the onset of the crisis, in March 2020, nearly all schools closed, moving education virtual, and remained closed for the rest of the school year. Throughout the 2020-21 school year, the majority of children remained in remote or partially remote (hybrid) school (USC Center for Economic and Social Research, 2021). Although some schools and many child care centers reopened over summer and fall 2020, they were subject to frequent, unpredictable closures as COVID-19 cases occurred in the setting or due to staff shortages when substantial numbers of staff were ill or required to quarantine. Anecdotal evidence suggests that parents and children struggled with these types of instability (Grose, 2021; Hsu, 2020), which compounded underlying stressors from the pandemic including job and income loss, material hardship, social isolation, and grief.

These disruptions to care and schooling mean that the COVID-19 crisis, while affecting all Americans, have hit families with children particularly hard. The impact is even more pronounced for populations of families with children that are particularly vulnerable due to marginalized economic or social identities (Ananat \& Gassman-Pines, 2020), including: hourly 
worker parents, who face unstable employment and earnings (Kurmann et al., 2020); families of color, whose communities face high rates of infection, inadequate medical care (Williams \& Collins, 2016), and pre-existing health disparities that worsen clinical outcomes (Haynes et al., 2020); and essential workers, who cannot work remotely and therefore cannot earn without childcare. Identifying the psychological effects of this crisis on children in such vulnerable families is essential for understanding the full effects of the COVID-19 pandemic as well as the effects of school closure policies across contexts.

To address this gap in the literature, this is the first study to examine daily variation in disruptions to care and school in the fall 2020 phase of the COVID-19 pandemic and identify disruptions' causal effects on daily child behavior problems. Further, this paper examines differences in the frequency and consequences of care and school disruptions for families using remote vs. in-person care, and for families of different racial and ethnic groups.

\section{Theoretical linkages between disruptions to care and school and children's behavior}

\section{problems}

Ecological Systems Theory posits that microsystems, or settings in which children spend time, have the most direct and immediate influence on development (Bronfenbrenner \& Evans, 2000; Bronfenbrenner \& Morris, 1998). Outside of their families, schools and child care settings are the primary microsystems in which young children in early childhood and early middle childhood spend time and, thus, are key developmental contexts. Within microsystems, the main drivers of child development are proximal processes—or interactions between individuals within those settings, such as between parents and children within families.

The pandemic radically altered children's school and care microsystems (Becker et al., 2020). In-person care and school settings have had different procedures, policies and experiences 
for students, such as mask wearing and social distancing (Sharfstein \& Morphew, 2020; Simon et al., 2020; The Hunt Institute, 2021). For remote schooling, the pandemic blurred the lines between settings, with both schooling and family interactions happening in the same physical space (Roy et al., 2021) and many parents juggled work and family responsibilities at the same time (Garbe et al., 2020).

Within the context of these broad changes, the COVID pandemic also caused disruptions to school and care on a daily basis. For example, child care centers that were still operating in person at times had to close temporarily due to school-based COVID clusters. For remote schooling, the need for technology led to additional disruptions for children, as many families did not have reliable internet access or devices (Auxier \& Anderson, 2020) and remote school relied on software that was difficult to manage (Domina et al., 2021).

An Ecological Systems Theory approach provides a framework for understanding how those day-to-day changes in the circumstances from day to day likely altered the proximal processes between children in early and middle childhood and others, primarily parents. When care or school is disrupted, parents may feel unable to provide support to their children's learning, a key role during the pandemic (Roy et al., 2021). Further, prior work shows that days with disruptions increased the difficulty of balancing work and family demands (Garbe et al., 2020), leading to increased parental stress (Ashforth et al., 2000; Pleck, 1995) and altered parentchild interactions (Berger et al., 1994; Williams \& Alliger, 1994). Each of these changes to family routines, parental mood, and parent-child interactions reflect daily alterations to proximal processes that are, in turn, related to children's behavior and well-being (Bass et al., 2009; Grzywacz \& Marks, 2000; Ilies et al., 2007). 
Ecological Systems Theory also acknowledges the relevance of contextual circumstances—such as access to social and material resources—in shaping developmental processes (Bronfenbrenner, 1993, 1995; Bronfenbrenner \& Morris, 1998; Tudge et al., 2009). Consistent with this approach, day-to-day pandemic-related disruptions were likely especially challenging for hourly service workers, who either lost work (e.g., clothing store employees) or had to continue working in person (e.g., "essential” workers at grocery stores). Thus, hourly service workers either dealt with unemployment or the strains of serving as an essential, customer-facing worker during the pandemic, both of which increase mental health risks (Pfefferbaum \& North, 2020). In addition, hourly service workers typically earn low wages, resulting in few economic resources to buffer daily pandemic-related strains.

A focus on contextual circumstances also suggests that dealing with day-to-day disruptions may have been especially challenging for families of color, for several reasons. First, people of color were more likely to contract and become severely ill with COVID-19 (Mackey et al., 2021), increasing strain on families of color and taxing family resources, and potentially leading to more daily reactivity to school and care disruptions. Second, even among lowerincome families, families of color have faced more pandemic-related hardships, such as food insecurity and increased debt, than non-Hispanic white families (Enriquez \& Goldstein, 2020) and wealth disparities by race that pre-dated the pandemic are well documented (Darity \& Nicholson, 2005). These hardships likely made balancing work and care/school demands on a daily basis more challenging for parents of color who had fewer economic resources with which to buffer other pandemic stressors. Finally, the COVID-19 pandemic coincided with renewed attention to racial justice and a national reckoning with racism in the United States, which, while 
important and long overdue, may also compound stress for families of color (Neighmond, 2020) and lead to larger daily effects when school or care is disrupted.

\section{Empirical findings}

The emergent research on child well-being during the COVID pandemic shows increased behavior problems and psychological distress overall. Behavior problems and psychological distress among young children have increased since the pandemic began (Ehrler et al., 2021; Gadermann et al., 2021; Steimle et al., 2021), and are correlated with cumulative exposure to pandemic-related stressors, such as job loss and family illness (Gassman-Pines et al., 2020). Parents’ psychological distress mediates the effects of pandemic-related stressors on child behavior problems (Koehler-Dauner et al., 2020; Marchetti et al., 2020) and the pandemic has had stronger effects on BIPOC children than white children (Clawson et al., 2021).

The growing literature on families' experiences with care and schooling during the pandemic shows that managing schooling has been challenging. Worry about schooling has been a major source of stress for parents (American Psychological Association, 2020). The less prepared parents felt to support children's learning at home and the more challenges they had with children, the worse their own self-reported mental health (Lee et al., 2021; Patrick et al., 2020). In fall 2020, parents with children in in-person schooling reported significantly higher levels of emotional distress than parents of children in remote only or hybrid schooling (Verlenden, 2021). Although child care for younger children was also disrupted by the pandemic (Ali et al., 2021; Jessen-Howard \& Workman, 2020), much less of the ongoing research has focused on linking child care changes to parent or child well-being.

\section{Daily diary studies}


The emerging literature on the effects of changes to school and care during the COVID19 pandemic has primarily described children's and parents' experiences in general in different care and school settings, or during the spring 2020 shift from in-person to remote instruction. A novel approach consistent with our theoretical conceptualization is to examine families' experiences of day-to-day variability in disruptions to care and school arrangements during the fall of 2020, in order to match the time scale of family life, capture daily variation in context and behavior, and investigate the proximal processes connecting disruptions to child behavior (Bolger et al., 2003). Investigating families’ daily lives can facilitate culturally grounded inquiries about family life in diverse families (Weisner, 2002). Using daily surveys also has methodological strengths, reducing recall bias and reducing the need for individuals to mentally aggregate across instances, both of which can result in underreporting (Bound et al., 2001; Mathiowetz et al., 2002; Winter, 2004).

Given the ongoing nature of the pandemic and the nascent literature about its effects, no research with this type of daily diary design has been used to examine daily disruptions to care and school arrangements and their consequences for children's daily well-being. Emerging literature focused on families' daily experiences at the beginning of the pandemic showed that family psychological well-being decreased markedly when school closures were initially announced (Gassman-Pines et al., 2020). Children’s daily behavior problems, including uncooperativeness and feelings of sadness or worry, increased at the time of school closures and were substantially higher after school closures than in the days prior to the closures (Steimle et al., 2021). No research, however, has examined daily variability in care and schooling during the pandemic, nor how care and school disruptions relate to daily child behavior. 
Research prior to the pandemic showed that daily changes to other aspects of families' contexts, including parents' work experiences, were related to both parent and, ultimately, child well-being. For example, among low-wage workers with children in early childhood, daily nighttime work hours and unexpected daily work schedules changes were related to worse daily parent mood (Ananat \& Gassman-Pines, 2021; Gassman-Pines, 2011). Parents were also harsher with their children and children displayed less positive behavior on days when their parents worked more nighttime hours (Gassman-Pines, 2011).

\section{Current study}

In order to understand how disruptions to care and schooling due to the COVID-19 pandemic have affected children's daily psychological well-being, this study examined four research questions in a sample of hourly service workers with young children, that is majority families of color. Identifying the psychological effects of this crisis on children in such vulnerable families is essential for understanding the full effects of the COVID-19 pandemic as well as the effects of school closure policies across contexts. The questions we examined included:

1. How common are disruptions to children's care and school arrangements from day to day? Do they vary for those in remote vs. in-person settings?

2. What are the daily effects of school/care disruptions on children's daily behavior problems?

3. How do these effects vary by families' racial and ethnic group? 


\section{Method}

\section{Sample Recruitment}

Individuals were eligible if they worked in an hourly service-industry position in a retail, food service, or hotel business in a given large U.S. city, had a child aged 2 to 7 at the time of enrollment (between August and November, 2019), and had a mobile phone that could send and receive basic SMS text messages. The sample was originally recruited for a study examining parents’ work schedule unpredictability and family well-being (for additional detail about this sample, see Gassman-Pines, Ananat, and Fitz-Henley 2020). Recruitment used a venue-based sampling approach, a commonly-used technique for producing generalizable samples of hard-toreach, un-rostered populations (Semaan, 2010). The key to successfully using this technique is generating a complete list of venues, which in this case were food service, retail and hospitality businesses in the city, provided by the Columbia University Earth Institute. We then constructed a sampling frame of venue (business) day-time units (VDTs), randomly selected VDTs, and systematically identified and recruited eligible individuals present in those VDTs, thus plausibly identifying a representative sample of the population (Muhib et al., 2001). To do so, at the time that study staff visited each business, they aimed to identify all workers who met sampling criteria who were at work at that time by approaching workers at each business, determining their eligibility, and asking those workers to direct them to any other employee with a young child who was currently at the venue. This strategy differs from snowball sampling in that study staff only recruited and only followed up with potentially eligible workers who were present at that time, to preserve random sampling.

\section{Procedure}

\section{Initial Procedure}


When first recruited, for the original study purpose of estimating effects of work schedules on family well-being, all participants were asked to complete 30 days of daily surveys and a one-time survey about demographic and household characteristics. All aspects of this study received human subjects approval from the Duke University Institutional Review Board.

\section{Current Study Data Collection Procedure}

Each participant from the original sample was contacted about participating in an additional 30-day wave of daily data collection, with recruitment and data collection occurring between September 8, 2020 and January 13, 2021 (when children were between 3 and 8). Participants were randomly assigned to one of six groups for initial invitations to participate in this wave. One group received an initial invitation each week, with outreach to all participants continuing through mid-December, 2020. 733 participants enrolled in this wave of data collection (70\% response rate). For the present analysis, we excluded parents who reported that they were not involved in their children's schooling or care $(N=54)$. Thus, the analysis sample for the present study was 679, with approximately 17,000 person-days for analysis (daily Ns varied slightly for the different outcomes and mediators due to missing data).

Respondents were prompted to report on each day's experiences with disruptions of care or school and their own and their child's well-being via SMS text message for 30 consecutive days. All survey materials used for this study were available in both English and Spanish.

The daily text surveys were programmed and automated by a third-party vendor. On the day of enrollment in this wave, participants received a text welcoming them to the start of the wave. The following day, the 30-day data collection period began. During that period, the first survey question was sent out each evening at 7:00PM. As soon as respondents sent back their answer to the first survey question, the second question was sent. This sequence was repeated 
until all questions and answers had been sent and received. A thank-you text sent at the end of the sequence let individuals know they had completed all that day's survey questions. If a respondent failed to reply to the first survey question, a reminder text was sent at 8:00PM. Additionally, if an individual started the survey but did not complete all questions, a reminder text was sent after two hours of inactivity (with the question on which the individual left off resent as part of the reminder) and then again after 14 hours of inactivity. Additional details about the text-message survey protocol are available in Gassman-Pines, Ananat, and Fitz-Henley (2020).

Participant compensation was structured to incentivize completion of all 30 daily surveys. Participants received \$1.50 for each survey completed, with bonuses of \$12 offered for each week with 7 completed surveys, and an additional completion bonus of $\$ 45$ for those who answered all 30 daily surveys and the one-time survey (see below). These incentives led to high rates of daily survey completion: the majority of participants (67\%) answered all thirty daily surveys; $90 \%$ of participants answer at least half of the daily surveys.

\section{Single Point-in-Time Survey Data Collection Procedure}

At the end of the 30-day daily data collection all participants were asked to complete a one-time survey that gathered information about children's school and care arrangements. All survey questions and answers were sent and received via SMS text message. Response rate to the one-time survey was very high ( $N=666$; 99\% response rate among analysis sample). Participants were offered \$25 for completing this one-time survey if they had not completed all daily surveys.

\section{Measures}

\section{Daily Survey Measure}


Disruptions to school and care. Parents were asked, “Did your child(ren)'s child care/school go smoothly today--happened on schedule, internet worked if needed, etc.?” The examples given were meant to emphasize irregularities in daily care and school arrangements outside of the participant's control. Answer choices were: Yes; Mostly; Somewhat; and Not at all. A dichotomous indicator representing disruption was constructed equal to 1 if the respondent answered Not at all, Somewhat, or Mostly and 0 if they answered Yes. In supplementary analyses (available upon request), we dichotomize this variable coding Somewhat and Not at all as 1 and Yes and Mostly as 0; results are substantially similar to those reported below.

Child behavior problems. Daily child uncooperative behavior was measured with a single item asking: “How much was your child uncooperative today?” Answers on a four-point scale included: Not at all, Just a little, Some, and A lot. This question was modified from an item in the Inattention/Overactivity with Aggression Conners Rating Scale (Loney \& Milich, 1982), which asks parents to rate how much the adjective describes their child "at this time.”

Daily child worry was measured with a single item asking: "How much did your child appear to be sad or worried today?” Answer choices on a four-point scale included: Not at all, Just a little, Some, and A lot. This question was modified from an item in the Preschool Behavior Questionnaire (Behar \& Stringfield, 1974), which asks parents to rate how much the child exhibits each behavior.

For both child behaviors, prior research has demonstrated the reliability and validity of multi-item scale versions adapted for measuring daily externalizing and internalizing behavior problems (Gassman-Pines, 2015). In the current study, single items were used to reduce respondent burden and attrition. Dichotomous indicator variables were set equal to 1 if the parent responded Some or A lot and 0 if the parent responded Not at all or Just a little. 
Parent Psychological Well-Being. Daily parental negative mood was measured with a single item asking: "How much of the time today did you feel fretful, angry, irritable, anxious, or depressed?” Answers on a three-point scale included: None of the time, Some of the time, and All of the time. This question was modified from a question with a four-week recall period from the Health Utilities Index (HUI) (Furlong et al., 2001; Horsman et al., 2003) (During the past four weeks how often did you feel fretful, angry, irritable, anxious or depressed?). The single item has been validated as a daily measure of negative mood as it is positively correlated with daily stressors, including daily food insecurity (Gassman-Pines \& Schenck-Fontaine, 2019) and daily work schedule disruptions [authors]; it increased substantially once COVID-19 restrictions were put into place [authors]. A dichotomous indicator was created equal to 1 for those who answered Some of the time or All of the time and 0 for those who answered None of the time.

Daily perceived negative sleep quality was measured with a single item also used in other daily survey studies (George et al., 2019), asking: “How well did you sleep last night?” Answers were on a 10-point scale from really badly to really well. We treat self-reported sleep quality as a measure of daily well-being, as perceived sleep quality is associated with daily affect (Bower et al., 2010). The sleep quality measure was reverse-coded so that higher numbers indicated worse perceived sleep quality. This measure has been validated, as it is correlated in expected directions with negative and positive daily mood, daily self-esteem (George et al., 2019) and daily work schedule disruptions, a daily stressor [authors].

Parenting Behavior. Difficulty supporting children’s care or learning was measured with a single item asking, "How hard was it to support your child(ren)'s participation in care/learning today?” Answer choices were: Not hard at all; Somewhat hard; and Very hard. A 
dichotomous indicator was created equal to 1 for those who answered Somewhat hard or Very hard and 0 for those who answered Not hard at all.

Harsh parenting was measured using two questions: "Did you punish your child today?” and "Did you lose your temper with your child today?" Both questions were answered either Yes or No. Dichotomous indicator variables were set equal to 1 if the parent responded Yes and 0 if the parent responded No.

\section{Single Point-in-Time Survey Measure of School and Care Context}

Parents were asked two questions: "Do you have a child/children enrolled in remote school?” and "Do you have a child/children in out-of-home care and/or school?” Both questions were answered either Yes or No. From those responses, a set of mutually exclusive indicators were created representing having children only in remote school, only in out-of-home care/school, both remote and out-of-home care/school, or neither.

\section{Other Analysis Variables}

At the outset of the study, participants were asked two questions about their racial and ethnic group: (1) “What is your race?” And (2) “Are you Hispanic/Latino/Latina?” For the first question, participants could select all that applied from the following list: Black/AfricanAmerican; White/Caucasian; Asian/Pacific Islander; Native American/American Indian/Alaska Native; and Other. From the responses to the two questions, three indicators were created: nonHispanic Black, non-Hispanic White; and Hispanic (any race).

An indicator variable for weekend was created that equaled 1 when that day was a Saturday or Sunday and 0 otherwise. An indicator variable for work day was created that equaled 1 when that day was a day that the parent worked and 0 otherwise.

\section{Analytic Plan}


First, we calculated descriptive statistics overall, by care/school type, and by family race and ethnicity.

Second, we estimated regression models with family fixed effects and standard errors clustered by family. All models included indicators for whether the day in question was a weekend day and whether the day was a work day. This model allowed us to estimate the average within-family effects of school and care disruptions, comparing child behaviors on days with and without disruptions for the same families. We also estimated subgroup regressions on the subsample that was reported to be in remote school only and the subsample that was reported to be in in-person care/school only. We estimated both the overall regressions and the care-type subsample regressions separately for families in which the respondent identified as Hispanic, Non-Hispanic Black, and Non-Hispanic White.

\section{Results}

\section{Sample Characteristics}

Sample characteristics appear in Table 1. Our sample is majority female, consistent with working in the service industry and with having custody of a young child (Gassman-Pines, Ananat, and Fitz-Henley 2020). About half are African-American and about one-fifth are Hispanic, consistent with being central-city hourly workers (Transportation Research Board and National Research Council, 1999). At the time of study enrollment, mean age was 31, consistent with being the parent of a young child (Gassman-Pines, Ananat, and Fitz-Henley 2020), and the modal education was 12 years, consistent with hourly service employment (Schwartz et al., 2015). About half of focal children are female; focal children were, on average, 5.0 years of age at the time of initial study enrollment $(S D=2.6$; range $=2-7)$, one year prior to the time period in the present study. Mean income prior to the pandemic was \$2,187 per month. 


\section{Descriptive Results}

Table 2 reports the distribution of learning modalities, both overall and by race. Remoteonly was the most common modality, reported by $44 \%$ of the sample overall; as public schools were entirely remote in the fall in the city of our study, that is not surprising. Next most common was a combination of in-person and remote learning, at 33\% of the sample. Another $13 \%$ of families reporting having only in-person care or schooling, while $11 \%$ reported that their family was currently using no care or school of either kind. For the most part, patterns of use by race and ethnicity were similar, and there were no race/ethnic differences in learning modality that were significant at conventional levels. However, the difference between the non-Hispanic Black rate $(11.7 \%)$ and non-Hispanic White rate (19.0\%) of using only in-person care/school was marginally statistically significant $(p<.10)$.

Table 3 reports the incidence of school and care disruptions overall, and by modality and race/ethnicity. The share of days on which school/care did not go as planned is strikingly high, at nearly a quarter of days (24.4\%) overall, as is the share of days when respondents reported it was difficult to support their child's learning (24.9\%). Across the month of the daily surveys, $77 \%$ of respondents reported at least one day when school/care did not go as planned, and 74\% reported at least one day when it was difficult to support their child's learning. While daily disruptions were frequent for all groups, they were more common for families using only remote learning (23.9\% of days) than for those using only in-person school/care (17.6\%), and share of days on which it was difficult to support learning were similarly elevated for remote (25.3\%) versus inperson (19.0\%); both differences were statistically significant $(p<.01)$. The daily share of families with a disruption throughout fall 2020 is shown in Figure 1. Disruptions decreased in September but then leveled off from mid-October through November. 
Overall, Hispanic parents reported the highest incidence and frequency of disruption and of difficulty supporting learning, while non-Hispanic Black parents’ reports were lower and nonHispanic White parents’ reports were in between. The difference between Hispanics’ and nonHispanic Blacks’ experiences were statistically significant for both measures overall and for all of the measures among remote learners; among families using in-person care, the differences were significant only for disruption frequency.

For all race/ethnic groups, the frequency of daily disruptions to learning was higher in remote than in in-person school/care. The differences were larger for Hispanics (40\% more frequent disruptions in remote than in in-person learning, $p<.001$ ) and non-Hispanic Blacks (53\% more frequent, $p<.001)$ than for non-Hispanic Whites $(18 \%$ more frequent, $p<.01)$.

\section{Daily Effects}

\section{Child behavior}

Table 4 shows the effect of daily school or care disruptions on child behavior, overall and by race/ethnicity and modality; overall effects are shown in Figure 2. A school or care disruption on a given day increased the share of children who were uncooperative "some or a lot today" by 9.1 percentage points, a striking increase from a base rate of $14.1 \%$. The effect was significantly larger for non-Hispanic Whites (11.9 percentage points) than for non-Hispanic Blacks (6.8 percentage points), but the effects were significantly different from zero and substantial in size for all race/ethnic groups. The pattern was similar for effects on the probability that the child appeared to be sad or worried some or a lot today, with an overall effect of 6.0 percentage points (nearly doubling the base rate of 6.7\%); the effect was significantly larger for non-Hispanic Whites (7.6 percentage points) than for Hispanics (4.1 percentage points), but again, effects were significantly different from zero and substantial in size for all race/ethnic groups. 
Effects of disruption were consistently significant across modalities and outcomes. They were often smaller for children in remote school, and larger for those in-person, than for children overall; the difference in effects for in-person versus remote was statistically significant for uncooperativeness overall and among non-Hispanic Black respondents (15.3\% versus 5.1\%).

\section{Parent mood}

Disruptions to school or care also strongly affected daily parent mood, increasing by a statistically significant 12.7 percentage points the share of respondents that day who said they felt fretful, angry, irritable, anxious, or depressed, from a base rate of $41.6 \%$. Effects were large and significant for all race/ethnic groups, with a higher point estimate for non-Hispanic White parents (16.7 percentage points) but no statistically significant differences in estimates between groups. Parent sleep difficulty also rose by a significant .056 SD $(p<.05)$ the night after a disruption. The magnitude of this impact appeared larger for parents of children in remote school only (0.134 SD, $p<0.01)$ than for parents of children attending school or care in person only (0.00 SD), but the difference was not statistically significant.

In contrast to effects on child behavior, effects of disruption on parent mood were similar across modalities overall—those using remote only had a 12.9 percentage point increase in feeling fretful, angry, irritable, anxious, or depressed after a disruption, while those using inperson only had a 13.5 percentage point increase. However, this consistency masked some differences by race. Non-Hispanic White parents experienced much worse effects from disruptions in in-person schooling (20.1 percentage points) than from disruptions in remote school (10.0 percentage points), while the point estimate for the effect on non-Hispanic Black parents from disruptions in remote schooling (15.3 percentage points) was larger than from 
disruptions in in-person (8.4 percentage points). However, neither of these differences was statistically significant.

\section{Parenting behaviors}

Perhaps not surprisingly given effects on mood, parents were more likely to lose their temper with their child on a day with a disruption. The overall increase was a statistically significant 5.6 percentage points from a base rate of 7.0\%. Effects were large and significant for all race/ethnic groups, but the effect for non-Hispanic White parents (8.6 percentage points) was significantly larger than for non-Hispanic Black parents (4.4 percentage points). Parents were also more likely to punish their child on a day with a disruption, with an increase of 4.5 percentage points from a base rate of 5.8\%. These effects were large and significant for all race/ethnic groups, but were larger for non-Hispanic White parents (8.2 percentage points; difference with non-Hispanic Black parents statistically significant at $p<.05$ ). Effects on parenting behaviors did not differ significantly by school/care modality.

\section{Discussion}

The COVID-19 pandemic has altered daily life for most families with young children. In particular, the closure or change in the nature of children's primary care and school settings has been one of the most substantial changes experienced by children themselves. Emergent evidence has shed light on the disruptions caused by the abrupt shift to remote schooling in the spring of 2020 (Bacher-Hicks et al., 2021; Domina et al., 2021). But there is little evidence about the experiences of disruptions as the pandemic persisted through the fall of 2020, nor about the effects of those disruptions on children's well-being. This study filled that gap by using daily survey data gathered in fall 2020 from a representative sample of hourly service workers with young children—a group with significant but common vulnerabilities— to shed light on the 
frequency of instances of disruptions to school and care, and the consequences of those disruptions for child behavior. The national public discussion about the relative risks to bringing children back to the classroom versus keeping them at home has had little rigorous evidence on which to rely. We document an aspect of daily mental health burden during the pandemic, unexpected disruptions in care and learning, and show its costs for child wellbeing. Results indicate that disruptions were common overall, occurred regularly for both remote and in-person settings, and were most common in remote learning. Further, children's behavior is negatively affected by disruptions, with evidence that effects are partially mediated by parents' challenges supporting children’s learning and by parents’ mood and behavior.

Research has shown how radically family life was altered when school abruptly closed in spring 2020 (Gassman-Pines et al., 2020; Gassman-Pines \& Gennetian, 2020; Steimle et al., 2021). Our results underscore that although many schools and child care facilities re-opened throughout summer and fall, families continued to experience instability in school and care throughout Fall 2020. On any given day, nearly 25\% of parents said that their care or school arrangement had not gone smoothly that day, and the vast majority of families had at least one day during the month of data collection on which care or school was disrupted. Our innovative daily survey design enabled us to reveal how common these disruptions were as they were occurring in daily life. This approach reduces recall bias and eliminates the need to ask people to mentally aggregate instances of disruptions, both of which can lead to undercounting these experiences (Bound et al., 2001; Mathiowetz et al., 2002).

Further, our results show that keeping children home to attend school remotely did not eliminate disruptions. In fact, although disruptions were common across school/care modality, we found that disruptions in remote learning were more common than disruptions in in-person 
care or school. This is likely due to challenges related to lack of stable and reliable internet access, dependable devices, user-friendly learning software, or other technological problems, which are more common among lower-income families (Auxier \& Anderson, 2020). Daily reports of parental difficulty supporting learning were also higher for families using remote than in-person, consistent with the unprecedented demands on parents of implementing remote education.

In terms of effects of these daily school and care disruptions on children's behavior problems, we found striking and consistent evidence that parents reported that their children had more behavior problems on days with a disruption than days without a disruption. Compared to days without disruptions, on days with disruptions parents reported a $71 \%$ increase in the share of children who exhibited uncooperativeness (an aspect of externalizing behavior problems) and a $112 \%$ increase in the share of children who seemed sad or worried (aspects of internalizing behavior problems). These large increases in child behavior problems are consistent with Ecological Systems Theory, as changes to children's microsystems are posited to have the largest and most direct effects on children’s development and well-being. For example, in contrast, prior research has shown that daily changes to the exosystem (parents' workplaces) have large effects on parent mood but do not affect children's daily behavior (Ananat et al., 2020).

More broadly beyond the pandemic, these results provide additional evidence of the harmful effects of daily unpredictability and instability in children’s everyday lives. Instability in the family setting has been linked to young children’s behavior problems (Fomby \& Mollborn, 2017). Further, research has shown that daily hassles and stressors in childhood are just as strongly related to later life health as major stressful life events (Odgers \& Jaffee, 2013). As developmental scientists seek to understand microsystem influences on child behavior, the 
disruptions and instability in school and care caused by the pandemic provide additional evidence of how chronic lower-level stressors can lead to child behavior problems. Future research should seek to investigate how these daily disruptions accumulate over time or having lasting effects beyond the day that they occur.

Finally, in terms of understanding the context of children's care and schooling in fall 2020, we found differences for families from different racial and ethnic groups. Although school/care disruptions were common for all families, Hispanic parents reported the highest rates of disruptions and non-Hispanic Black parents reported the lowest. Non-Hispanic Black families also experienced somewhat milder effects of disruptions on well-being than did other families, while non-Hispanic White families experienced somewhat stronger effects than did other families. A complete understanding of the reasons underlying these differences will require further study but we note that, consistent with prior literature (e.g., Akee et al., 2019), the nonHispanic white families in our sample had more advantages at the outset of the study, including slightly higher levels of education and being more likely to be living with a spouse or partner. It is possible that during the pandemic loss of access to some of the supports related to those advantages may have made disruptions experienced during the pandemic more salient.

Nonetheless, across race/ethnicity groups all families experienced severe—large, statistically significant, negative—effects from disruptions on parent mood, child mood, and parenting behaviors. Moreover, across all racial/ethnic groups families were $36 \%$ more likely to experience daily disruptions in remote school, with even greater increases for families of color. These findings can inform policymakers deciding how to prioritize efforts to make a safe and stable return to in-person school available to families as well as bolster support for those who must learn remotely. 


\section{Limitations}

While our study demonstrates the impact of daily COVID-related disruptions on a vulnerable population, the sample population was limited and targeted. Families in which parents were hourly workers in other industries or salaried workers may have had different experiences with school and child care during the fall of 2020. Further, our findings are local to a particular major city. The experience of the pandemic may differ from city to city, based on infection prevalence and governmental and social response. Finally, we used a simplified approach so as to allow us to have a large sample answer this question daily. However, this meant that we were not able to ask detailed follow-up questions, so we are not able to parse out from this data whether a given disruption was due to internet failure, COVID-19 cases, or some other specific source.

\section{Conclusion}

Despite these limitations, however, this study provides compelling new evidence of disruptions to important microsystem settings for young children - school and child care during the ongoing COVID-19 pandemic. There has been little evidence about the experiences of disruptions to children's care and school arrangements as the pandemic persisted through the 2020-2021 school year, nor about the effects of those disruptions on child and family well-being. By using innovative daily survey data gathered in the fall of 2020 from a representative sample of hourly service workers with young children, we are able to shed light on the frequency of disruptions to school and care, and the consequences of those disruptions for child and parent mental health, among a group of families with significant but common vulnerabilities. While previous work had documented that universal, short closures (such as snow days) had few effects on children (Goodman, 2014), we document that frequent, unexpected disruptions in care and 
learning have significantly contributed to the daily burden for families during the pandemic. Policies to increase the safety, accessibility, and predictability of in-person learning hold promise to reduce disruptions. Moreover, as school districts oversee a school year in which many experience intermittent classroom or school-wide closures, additional support and resources for families in remote modes may be needed to stabilize their day-to-day experiences. Finally, this research provides further evidence on, as well as identifying additional sources of, emotional distress among children that schools and other child-serving organizations will need to address as they try to repair the damage incurred in the pandemic. 
Effects of daily school and care disruptions on child mental health - 26

\section{References}

Ali, U., Herbst, C. M., \& Makridis, C. A. (2021). The impact of COVID-19 on the US child care market: Evidence from stay-at-home orders. Economics of Education Review, 102094.

American Psychological Association. (2020). Stress in America 2020. American Psychological Association. https://www.apa.org/news/press/releases/stress/2020/sia-mental-healthcrisis.pdf

Ananat, E. O., \& Gassman-Pines, A. (2020). Snapshot of the COVID Crisis Impact on Working Families. https://econofact.org/snapshot-of-the-covid-crisis-impact-on-working-families

Ananat, E. O., \& Gassman-Pines, A. (2021). Work schedule unpredictability: daily occurrence and effects on working parents' well-being Journal of Marriage and Family, 81(1), 1026.

Ananat, E. O., Gassman-Pines, A., \& Fitz-Henley II, J. (2020). The Effects of Service-Industry Work Schedule Unpredictability on Families Association for Public Policy Analysis and Management Fall Research Conference, Virtual.

Ashforth, B. E., Kreiner, G. E., \& Fugate, M. (2000). All in a day’s work: Boundaries and micro role transitions. Academy of Management Review, 25, 472-491.

Auxier, B., \& Anderson, M. (2020). As schools close due to the coronavirus, some US students face a digital 'homework gap'. Pew Research Center, 16, 1-8.

Bacher-Hicks, A., Goodman, J., \& Mulhern, C. (2021). Inequality in household adaptation to schooling shocks: Covid-induced online learning engagement in real time. Journal of Public Economics, 193, 104345. 
Bass, B. L., Butler, A. B., Grzywacz, J. G., \& Linney, K. D. (2009). Do job demands undermine parenting? A daily analysis of spillover and crossover effects. Family Relations, 58, 201215.

Becker, S. P., Breaux, R., Cusick, C. N., Dvorsky, M. R., Marsh, N. P., Sciberras, E., \& Langberg, J. M. (2020). Remote Learning During COVID-19: Examining School Practices, Service Continuation, and Difficulties for Adolescents With and Without Attention-Deficit/Hyperactivity Disorder. Journal of Adolescent Health, 67(6), 769-777. https://doi.org/https://doi.org/10.1016/j.jadohealth.2020.09.002

Behar, L., \& Stringfield, S. (1974). A behavior rating scale for the preschool child. Developmental Psychology, 10, 601-610. https://doi.org/10.1037/h0037058

Berger, P., Cook, A., DelCampo, R., Herrera, R., \& Weigel, R. (1994). Family/work roles' relation to perceived stress: Do gender and ethnicity matter? Journal of Family and Economic Issues, 15(3), 223-242. https://doi.org/10.1007/bf02353629

Bolger, N., Davis, A., \& Rafaeli, E. (2003). Diary methods: Capturing life as it is lived. Annual Review of Psychology, 54, 579-616.

\section{https://doi.org/10.1146/annurev.psych.54.101601.145030}

Bolger, N., \& Laurenceau, J.-P. (2013). Intensive longitudinal methods: An introduction to diary and experience sampling research. Guilford Press.

Bound, J., Brown, C., \& Mathiowetz, N. (2001). Measurement error in survey data. In Handbook of econometrics (Vol. 5, pp. 3705-3843). Elsevier.

Bower, B., Bylsma, L. M., Morris, B. H., \& Rottenberg, J. (2010). Poor reported sleep quality predicts low positive affect in daily life among healthy and mood-disordered persons. Journal of sleep research, 19(2), 323-332. 
Bronfenbrenner, U. (1993). The ecology of cognitive development: Research models and fugitive findings. In R. Wonziak \& K. Fischer (Eds.), Development in context: Acting and thinking in specific environments (pp. 3-46). Erlbaum.

Bronfenbrenner, U. (1995). Developmental ecology through space and time: A future perspective. In P. Moen, J. Elder, Glen H., \& K. Luscher (Eds.), Examining lives in context: Perspectives on the ecology ofhuman development (pp. 619-647). American Psychological Association.

Bronfenbrenner, U., \& Evans, G. W. (2000). Developmental Science in the 21st Century: Emerging Questions, Theoretical Models, Research Designs and Empirical Findings. Social Development, 9(1), 115-125. https://doi.org/10.1111/1467-9507.00114

Bronfenbrenner, U., \& Morris, P. A. (1998). The ecology of developmental processes. In W. Damon \& R. M. Lerner (Eds.), Handbook of child psychology: Theoretical models of human development (pp. 993-1028). John Wiley \& Sons.

Bureau of Labor Statistics. (2020). Unemployment insurance weekly claims. https://www.dol.gov/ui/data.pdf

Center for Systems Science and Engineering at Johns Hopkins University. (2020). COVID-19 Dashboard. https://gisanddata.maps.arcgis.com/apps/opsdashboard/index.html\#/bda7594740fd40299 $\underline{423467 \mathrm{~b} 48 \mathrm{e} 9 \mathrm{ecf} 6}$

Clawson, A. H., Nwankwo, C. N., Blair, A. L., Pepper-Davis, M., Ruppe, N. M., \& Cole, A. B. (2021). COVID-19 Impacts on Families of Color and Families of Children With Asthma. Journal of Pediatric Psychology. 
Darity, W. A., Jr. , \& Nicholson, M. J. (2005). Racial wealth inequality and the black family. In V. McLoyd, N. E. Hill, \& K. A. Dodge (Eds.), African American family life: Ecological and cultural diversity (pp. 78-85). The Guilford Press.

Domina, T., Renzulli, L., Murray, B., Garza, A. N., \& Perez, L. (2021). Remote or Removed: Predicting Successful Engagement with Online Learning during COVID-19. Socius, 7, 2378023120988200.

Ehrler, M., Werninger, I., Schnider, B., Eichelberger, D. A., Naef, N., Disselhoff, V., Kretschmar, O., Hagmann, C. F., Latal, B., \& Wehrle, F. M. (2021). Impact of the COVID-19 pandemic on children with and without risk for neurodevelopmental impairments. Acta Paediatrica, 110(4), 1281-1288.

Enriquez, D., \& Goldstein, A. (2020). COVID-19’s Socioeconomic Impact on Low-Income Benefit Recipients: Early Evidence from Tracking Surveys. Socius, 6, 2378023120970794.

Fomby, P., \& Mollborn, S. (2017). Ecological Instability and Children’s Classroom Behavior in Kindergarten. Demography, 54(5), 1627-1651. https://doi.org/10.1007/s13524-017-0602$\underline{2}$

Furlong, W. J., Feeny, D. H., Torrance, G. W., \& Barr, R. D. (2001). The Health Utilities Index (HUI $\left.{ }^{\circledR}\right)$ system for assessing health-related quality of life in clinical studies. Annals of medicine, 33(5), 375-384.

Gadermann, A. C., Thomson, K. C., Richardson, C. G., Gagné, M., McAuliffe, C., Hirani, S., \& Jenkins, E. (2021). Examining the impacts of the COVID-19 pandemic on family mental health in Canada: findings from a national cross-sectional study. BMJ open, 11(1), e042871. 
Garbe, A., Ogurlu, U., Logan, N., \& Cook, P. (2020). COVID-19 and remote learning: Experiences of parents with children during the pandemic. American Journal of Qualitative Research, 4(3), 45-65.

Gassman-Pines, A. (2011). Low-income mothers’ nighttime and weekend work: Daily associations with child behavior, mother-child interactions and mood. Family Relations, 60, 15-29. https://doi.org/10.1111/j.1741-3729.2010.00630.x

Gassman-Pines, A. (2015). Effects of Mexican immigrant parents’ daily workplace discrimination on child behavior and family functioning. Child Development, 18, 11751190.

Gassman-Pines, A., Ananat, E. O., \& Fitz-Henley, J. (2020). COVID-19 and parent-child psychological well-being. Pediatrics, 146(4). https://doi.org/10.1542/peds.2020-007294

Gassman-Pines, A., \& Gennetian, L. (2020). COVID-19 Job and Income Loss Jeopardize Child Well-Being: Income Support Policies Can Help. SRCD Child Evidence Brief, 9.

Gassman-Pines, A., \& Schenck-Fontaine, A. (2019). Daily Food Insufficiency and Worry among Economically Disadvantaged Families with Young Children. Journal of Marriage and Family.

George, M. J., Rivenbark, J. G., Russell, M. A., Ng'eno, L., Hoyle, R. H., \& Odgers, C. L. (2019). Evaluating the Use of Commercially Available Wearable Wristbands to Capture Adolescents’ Daily Sleep Duration. Journal of Research on Adolescence, 29(3), 613-626.

Grose, J. (2021, February 4). America’s Mothers Are in Crisis. Is anyone listening to them? The New York Times. https://www.nytimes.com/interactive/2021/02/04/parenting/working$\underline{\text { moms-coronavirus.html }}$ 
Grzywacz, J. G., \& Marks, N. F. (2000). Reconceptualizing the work-family interface: an ecological perspective on the correlates of positive and negative spillover between work and family. Journal of Occupational Health Psychology, 5, 111-126. https://doi.org/10.1037/1076-8998.5.1.111

Haynes, N., Cooper, L. A., \& Albert, M. A. (2020). At the Heart of the Matter: Unmasking and Addressing COVID-19’s Toll on Diverse Populations. Circulation, 142.

Horsman, J., Furlong, W., Feeny, D., \& Torrance, G. (2003). The Health Utilities Index (HUI®): concepts, measurement properties and applications. Health and quality of life outcomes, 1(1), 54. https://doi.org/10.1186/1477-7525-1-54

Hsu, A. (2020). 'This Is Too Much': Working Moms Are Reaching The Breaking Point During The Pandemic. NPR. https://www.npr.org/2020/09/29/918127776/this-is-too-muchworking-moms-are-reaching-the-breaking-point-during-the-pandemi

Ilies, R., Schwind, K. M., Wagner, D. T., Johnson, M. D., DeRue, D. S., \& Ilgen, D. R. (2007). When can employees have a family life? The effects of daily workload and affect on work-family conflict and social behaviors at home. Journal of Applied Psychology, 92(5), 1368-1379. https://doi.org/10.1037/0021-9010.92.5.1368

Jessen-Howard, S., \& Workman, S. (2020). Coronavirus Pandemic Could Lead to Permanent Loss of Nearly 4.5 Million Child Care Slots. https://www.americanprogress.org/issues/earlychildhood/news/2020/04/24/483817/coronavirus-pandemic-lead-permanent-loss-nearly4-5-million-child-care-slots/ 
Koehler-Dauner, F., Clemens, V., Lange, S., Ziegenhain, U., \& Fegert, J. M. (2020). Mothers Daily Perceived Stress Influences their Children’s Mental Health During SARS-CoV-2pandemic.

Kurmann, A., Lale, E., \& Ta, L. (2020). The impact of covid-19 on us employment and hours: Real-time estimates with homebase data. May). http://www. andrekurmann. com/hb_covid.

Lee, S. J., Ward, K. P., Chang, O. D., \& Downing, K. M. (2021). Parenting activities and the transition to home-based education during the COVID-19 pandemic. Children and Youth Services Review, 122, 105585.

Loney, J., \& Milich, R. (1982). Hyperactivity, inattention, and aggression in clinical practice. In M. Wolraich \& D. K. Rough (Eds.), Advances in development and behavioral pediatrics (Vol. 3, pp. 113-147). JAI Press.

Mackey, K., Ayers, C. K., Kondo, K. K., Saha, S., Advani, S. M., Young, S., Spencer, H., Rusek, M., Anderson, J., \& Veazie, S. (2021). Racial and ethnic disparities in COVID-19-related infections, hospitalizations, and deaths: A systematic review. Annals of internal medicine, 174(3), 362-373.

Marchetti, D., Fontanesi, L., Di Giandomenico, S., Mazza, C., Roma, P., \& Verrocchio, M. C. (2020). The Effect of Parent Psychological Distress on Child Hyperactivity/Inattention During the COVID-19 Lockdown: Testing the Mediation of Parent Verbal Hostility and Child Emotional Symptoms. Frontiers in Psychology, 11, 3417.

Mathiowetz, N., Brown, C., \& Bound, J. (2002). Measurement error in surveys of the lowincome population. Studies of welfare populations: Data collection and research issues, 157-194. 
Muhib, F. B., Lin, L. S., Stueve, A., Miller, R. L., Ford, W. L., Johnson, W. D., Smith, P. J., \& Community Intervention Trial for Youth Study Team. (2001). A venue-based method for sampling hard-to-reach populations. Public health reports, 116(1 suppl), 216-222.

National Academy for State Health Policy. (2020). Chart: Each State’s COVID-19 Reopening and Reclosing Plans and Mask Requirements. https://www.nashp.org/governorsprioritize-health-for-all/

Neighmond, P. (2020). 'Change Can Happen': Black Families On Racism, Hope And Parenting. https://www.npr.org/sections/health-shots/2020/07/19/891517857/change-can-happenblack-families-on-racism-hope-and-parenting

Odgers, C. L., \& Jaffee, S. R. (2013). Routine versus catastrophic influences on the developing child. Annual Review of Public Health, 34, 29-48.

Patrick, S. W., Henkhaus, L. E., Zickafoose, J. S., Lovell, K., Halvorson, A., Loch, S., Letterie, M., \& Davis, M. M. (2020). Well-being of parents and children during the COVID-19 pandemic: a national survey. Pediatrics, 146(4). https://doi.org/10.1542/peds.2020$\underline{016824}$

Pfefferbaum, B., \& North, C. S. (2020). Mental health and the Covid-19 pandemic. New England Journal of Medicine, 383(6), 510-512.

Pleck, J. H. (1995). Work roles, family roles and well-being: Current conceptual perspectives. In G. L. Brown \& J. F. Pittman (Eds.), The work and family interface: Toward a contextual effects perspective (pp. 17-22). National Council on Family Relations.

Roy, A., Breaux, R., Sciberras, E., Patel, P., Ferrara, E., Shroff, D., Cash, A., Dvorsky, M., Langberg, J., \& Quach, J. (2021). Key Strategies, Challenges, and Benefits of Remote Learning Expressed by Parents During the COVID-19 Pandemic. 
Schwartz, A., Wasser, M., Gillard, M., \& Paarlberg, M. (2015). Unpredictable, unsustainable: The impact of employers' scheduling practices in D.C.

Semaan, S. (2010). Time-space sampling and respondent-driven sampling with hard-to-reach populations. Methodological Innovations Online, 5(2), 60-75.

Sharfstein, J. M., \& Morphew, C. C. (2020). The urgency and challenge of opening K-12 schools in the fall of 2020. Jama, 324(2), 133-134.

Simon, A., Huebner, J., Berner, R., Munro, A. P., Exner, M., Huppertz, H.-I., \& Walger, P. (2020). Measures to maintain regular operations and prevent outbreaks of SARS-CoV-2 in childcare facilities or schools under pandemic conditions and co-circulation of other respiratory pathogens. GMS hygiene and infection control, 15.

Steimle, S., Gassman-Pines, A., Johnson, A. D., Hines, C., \& Ryan, R. M. (2021). Understanding patterns of food insecurity and family wellbeing amid the COVID-19 pandemic using daily surveys.

The Hunt Institute. (2021). State Child Care Actions. https://hunt-institute.org/covid-19resources/state-child-care-actions-covid-19/

Transportation Research Board and National Research Council. (1999). Governance and Opportunity in Metropolitan America. National Academies Press.

\section{https://doi.org/https://doi.org/10.17226/6038}

Tudge, J. R., Mokrova, I., Hatfield, B. E., \& Karnik, R. B. (2009). Uses and misuses of Bronfenbrenner's bioecological theory of human development. Journal of Family Theory \& Review, 1(4), 198-210.

USC Center for Economic and Social Research. (2021). Understanding Coronavirus in America. https://covid19pulse.usc.edu/ 
Verlenden, J. V. (2021). Association of Children's Mode of School Instruction with Child and Parent Experiences and Well-Being During the COVID-19 Pandemic_-COVID Experiences Survey, United States, October 8-November 13, 2020. MMWR. Morbidity and Mortality Weekly Report, 70.

Weisner, T. S. (2002). Ecocultural understanding of children's developmental pathways. Human development, 45(4), 275-281.

Williams, D. R., \& Collins, C. (2016). Racial residential segregation: a fundamental cause of racial disparities in health. Public health reports.

Williams, K. J., \& Alliger, G. M. (1994). Role stressors, mood spillover, and perceptions of work-family conflict in employed parents. Academy of Management Journal, 37, 837868.

Winter, J. (2004). Response bias in survey-based measures of household consumption. Economics Bulletin, 3(9), 1-12. 
Table 1. Sample characteristics and descriptive statistics

\begin{tabular}{lcc}
\hline & Mean & St. Dev. \\
Demographics at study enrollment (Fall 2019) & & \\
\hline Parent age (years) & 30.8 & 6.9 \\
Parent female & $84.0 \%$ & \\
Race/ethnicity & & \\
$\quad$ Hispanic (of any race) & $22.0 \%$ & \\
African-American (non-Hispanic) & $50.5 \%$ & \\
$\quad$ White (non-Hispanic) & $17.9 \%$ & \\
Asian (non-Hispanic) & $2.9 \%$ & \\
Multi-racial (non-Hispanic) & $2.3 \%$ & \\
Education: & & \\
< high school education & $8.7 \%$ & \\
Exactly a high school education & $62.0 \%$ & \\
> high school education & $29.3 \%$ & \\
Monthly household income & $\$ 2,187$ & $\$ 1,648$ \\
Child characteristics & & \\
Age (years) & 5.0 & 2.6 \\
Female & $50 \%$ &
\end{tabular}

Daily family measures during current study (Fall 2020)

Daily child behavior measures

Uncooperative

$14.1 \%$

Sad/worried

$6.7 \%$

Daily parent measures

Fretful, angry, irritable, anxious, depressed

$41.6 \%$

Difficulty sleeping (1-10 scale)

4.1

2.4

Daily parenting behaviors

Lost temper with child

$7.0 \%$

Punished child

$5.8 \%$

$$
\begin{array}{rc}
N(\text { persons })= & 679 \\
N(\text { person-days })= & 17,077
\end{array}
$$


Table 2. Distribution of school/care modalities, overall and by race

\begin{tabular}{|c|c|c|c|c|}
\hline & Remote Only & In Person Only & Both & Neither \\
\hline \multicolumn{5}{|l|}{ All families } \\
\hline share & $43.6 \%$ & $13.0 \%$ & $32.7 \%$ & $10.7 \%$ \\
\hline standard error & $(1.9 \%)$ & $(1.3 \%)$ & $(1.8 \%)$ & $(1.2 \%)$ \\
\hline $\mathrm{N}$ & 285 & 85 & 214 & 70 \\
\hline \multicolumn{5}{|l|}{ Hispanic families } \\
\hline share & $41.3 \%$ & $14.5 \%$ & $30.4 \%$ & $13.8 \%$ \\
\hline standard error & $(4.2 \%)$ & (3.0\%) & (3.9\%) & $(2.9 \%)$ \\
\hline $\mathrm{N}$ & 57 & 20 & 42 & 19 \\
\hline \multicolumn{5}{|c|}{ Non-Hispanic Black families } \\
\hline share & $42.9 \%$ & $11.7 \%$ & $34.8 \%$ & $10.5 \%$ \\
\hline standard error & $(2.7 \%)$ & $(1.8 \%)$ & $(2.6 \%)$ & $(1.7 \%)$ \\
\hline $\mathrm{N}$ & 143 & 39 & 116 & 35 \\
\hline \multicolumn{5}{|c|}{ Non-Hispanic White families } \\
\hline share & $43.0 \%$ & $19.0 \%$ & $30.6 \%$ & $7.4 \%$ \\
\hline standard error & $(4.5 \%)$ & (3.6\%) & $(4.2 \%)$ & $(2.4 \%)$ \\
\hline $\mathrm{N}$ & 52 & 23 & 37 & 9 \\
\hline
\end{tabular}


Table 3. Incidence and frequency of school/care disruptions by modality and race/ethnicity

\begin{tabular}{|c|c|c|c|c|}
\hline & & \multicolumn{3}{|c|}{ Race/Ethnicity } \\
\hline & $\underline{\text { All }} \underline{\underline{\text { families }}}$ & $\underline{\text { Hispanic }}$ & $\frac{\frac{\text { Non- }}{\text { Hispanic }}}{\underline{\text { Black }}}$ & $\frac{\frac{\text { Non- }}{\text { Hispanic }}}{\underline{\text { White }}}$ \\
\hline \multicolumn{5}{|l|}{ Across all modalities } \\
\hline \multicolumn{5}{|l|}{ Days with: } \\
\hline School/care disruption & $\begin{array}{l}24.4 \% \\
(.3 \%)\end{array}$ & $\begin{array}{l}30.8 \% \\
(.8 \%)\end{array}$ & $\begin{array}{l}21.5 \% \\
(.5 \%)\end{array}$ & $\begin{array}{l}22.2 \% \\
(.7 \%)\end{array}$ \\
\hline Difficulty supporting learning & $\begin{array}{c}24.9 \% \\
(.3 \%)\end{array}$ & $\begin{array}{c}28.1 \% \\
(.7 \%)\end{array}$ & $\begin{array}{l}22.1 \% \\
(.5 \%)\end{array}$ & $\begin{array}{l}24.7 \% \\
(.8 \%)\end{array}$ \\
\hline \multicolumn{5}{|l|}{$\begin{array}{l}\text { Parents reporting at least } 1 \text { instance during } \\
\text { the month of: }\end{array}$} \\
\hline School/care disruption & $\begin{array}{l}77.3 \% \\
(1.6 \%)\end{array}$ & $\begin{array}{l}81.4 \% \\
(3.2 \%)\end{array}$ & $\begin{array}{l}72.3 \% \\
(2.5 \%)\end{array}$ & $\begin{array}{l}78.8 \% \\
(3.8 \%)\end{array}$ \\
\hline Difficulty supporting learning & $\begin{array}{l}73.9 \% \\
(1.7 \%)\end{array}$ & $\begin{array}{l}81.4 \% \\
(3.2 \%)\end{array}$ & $\begin{array}{l}69.3 \% \\
(2.5 \%)\end{array}$ & $\begin{array}{l}72.0 \% \\
(4.1 \%)\end{array}$ \\
\hline \multicolumn{5}{|l|}{ Remote only } \\
\hline School/care disruption & $\begin{array}{l}23.9 \% \\
(.5 \%)\end{array}$ & $\begin{array}{l}29.9 \% \\
(1.2 \%)\end{array}$ & $\begin{array}{l}19.4 \% \\
(.7 \%)\end{array}$ & $\begin{array}{l}25.0 \% \\
(1.1 \%)\end{array}$ \\
\hline Difficulty supporting learning & $\begin{array}{c}25.3 \% \\
(.5 \%)\end{array}$ & $\begin{array}{l}30.4 \% \\
(1.2 \%)\end{array}$ & $\begin{array}{c}20.2 \% \\
(.7 \%)\end{array}$ & $\begin{array}{l}26.1 \% \\
(1.2 \%)\end{array}$ \\
\hline \multicolumn{5}{|l|}{$\begin{array}{l}\text { Parents reporting at least } 1 \text { instance during } \\
\text { the month of: }\end{array}$} \\
\hline School/care disruption & $\begin{array}{l}78.3 \% \\
(2.4 \%)\end{array}$ & $\begin{array}{l}86.0 \% \\
(4.6 \%)\end{array}$ & $\begin{array}{l}71.2 \% \\
(3.9 \%)\end{array}$ & $\begin{array}{l}80.4 \% \\
(5.6 \%)\end{array}$ \\
\hline Difficulty supporting learning & $\begin{array}{l}75.1 \% \\
(2.6 \%)\end{array}$ & $\begin{array}{l}84.2 \% \\
(4.9 \%)\end{array}$ & $\begin{array}{l}69.8 \% \\
(3.9 \%)\end{array}$ & $\begin{array}{l}70.6 \% \\
(6.4 \%)\end{array}$ \\
\hline \multicolumn{5}{|l|}{ In-person only } \\
\hline School/care disruption & $\begin{array}{l}17.6 \% \\
(.8 \%)\end{array}$ & $\begin{array}{l}21.4 \% \\
(1.7 \%)\end{array}$ & $\begin{array}{l}12.7 \% \\
(1.1 \%)\end{array}$ & $\begin{array}{l}20.3 \% \\
(1.7 \%)\end{array}$ \\
\hline Difficulty supporting learning & $\begin{array}{c}19.0 \% \\
(.8 \%)\end{array}$ & $\begin{array}{l}17.3 \% \\
(1.6 \%)\end{array}$ & $\begin{array}{l}19.9 \% \\
(1.3 \%)\end{array}$ & $\begin{array}{l}20.3 \% \\
(1.7 \%)\end{array}$ \\
\hline \multicolumn{5}{|l|}{$\begin{array}{l}\text { Parents reporting at least } 1 \text { instance during } \\
\text { the month of: }\end{array}$} \\
\hline School/care disruption & $\begin{array}{l}69.4 \% \\
(5.0 \%)\end{array}$ & $\begin{array}{c}60.0 \% \\
(11.2 \%)\end{array}$ & $\begin{array}{l}69.4 \% \\
(7.8 \%)\end{array}$ & $\begin{array}{l}81.0 \% \\
(8.8 \%)\end{array}$ \\
\hline Difficulty supporting learning & $\begin{array}{l}64.7 \% \\
(5.2 \%) \\
\end{array}$ & $\begin{array}{l}75.0 \% \\
(9.9 \%) \\
\end{array}$ & $\begin{array}{l}66.7 \% \\
(8.0 \%) \\
\end{array}$ & $\begin{array}{c}57.1 \% \\
(11.1 \%) \\
\end{array}$ \\
\hline$N$ (person-days) & 17077 & 3644 & 7981 & 3262 \\
\hline
\end{tabular}


Effects of daily school and care disruptions on child mental health - 39

$\begin{array}{lllll}N \text { (persons) } & 679 & 145 & 332 & 118\end{array}$

Note. Standard errors in parentheses. 
Table 4. Effect of school/care disruption today on daily outcomes, by modality and race/ethnicity

\section{All modalities}

Child behavior:

Child was uncooperative some or a lot today

Child appeared to be sad or worried some or a lot today

Parent wellbeing:

Felt fretful angry irritable anxious or depressed today

Sleep Difficulty the night following this day - normalized

Parenting behaviors:

Lost temper today

Punished child today

\section{Remote only}

Child behavior:

Child was uncooperative some or a lot today

Child appeared to be sad or worried some or a lot today

Parent wellbeing:

Felt fretful angry irritable anxious or depressed today

Sleep Difficulty the night following this day - normalized

Parenting behaviors:

Lost temper today

\begin{tabular}{|c|c|c|c|}
\hline \multirow[b]{2}{*}{$\begin{array}{c}\text { All } \\
\text { families }\end{array}$} & \multicolumn{3}{|c|}{ By Race/Ethnicity } \\
\hline & Hispanic & $\frac{\frac{\text { Non- }}{\text { Hispanic }}}{\text { Black }}$ & $\frac{\frac{\text { Non- }}{\text { Hispanic }}}{\underline{\text { White }}}$ \\
\hline $.091^{* * *}$ & $.092^{* * *}$ & $.068 * * *$ & $.119 * * *$ \\
\hline '(.01) & '(.023) & '(.014) & '(.023) \\
\hline $.06 * * *$ & $.041^{* *}$ & $.055^{* * *}$ & $.076^{* * *}$ \\
\hline '(.007) & '(.015) & '(.011) & '(.018) \\
\hline $.127^{* * *}$ & $.122^{* * *}$ & $.112^{* * *}$ & $.167^{* * *}$ \\
\hline '(.013) & '(.029) & '(.02) & '(.034) \\
\hline $.056^{*}$ & 0.06 & .067 & .026 \\
\hline '(.027) & '(.061) & '(.043) & '(.062) \\
\hline $.056^{* * *}$ & $.049 *$ & $.044^{* * *}$ & $.086^{* * *}$ \\
\hline '(.008) & '(.019) & '(.011) & '(.018) \\
\hline $.045^{* * *}$ & $.037 * *$ & $.033 * *$ & $.082^{* * *}$ \\
\hline '(.007) & '(.014) & '(.01) & '(.023) \\
\hline $.07 * * *$ & $.062+$ & $.045^{* *}$ & $.119 * *$ \\
\hline '(.014) & '(.037) & '(.017) & '(.039) \\
\hline $.051^{* * *}$ & 0.023 & $.049 * * *$ & $.038^{*}$ \\
\hline '(.009) & '(.015) & '(.013) & '(.019) \\
\hline $.129 * * *$ & $.146 * *$ & $.153^{* * *}$ & $.1^{*}$ \\
\hline '(.019) & '(.049) & '(.03) & '(.043) \\
\hline $.134^{* *}$ & 0.151 & $.166^{* *}$ & 0.082 \\
\hline '(.041) & '(.102) & '(.061) & '(.098) \\
\hline $.046^{* * *}$ & 0.024 & $.041 * *$ & $.053+$ \\
\hline '(.011) & '(.025) & '(.014) & '(.028) \\
\hline
\end{tabular}


Effects of daily school and care disruptions on child mental health - 41

Punished child today

\section{In-person only}

Child appeared to be sad or worried some or a lot today

Parent wellbeing:

Felt fretful angry irritable anxious or depressed today

Sleep Difficulty the night following this day - normalized

Parenting behaviors:

Lost temper today

Punished child today
Child behavior:

Child was uncooperative some or a lot today

$\begin{array}{cccc}.041^{* * *} & 0.015 & .037^{* *} & .072+ \\ '(.011) & '(.016) & '(.013) & '(.042)\end{array}$

$\begin{array}{llll}.135 * * * & .136 * & .157^{* *} & .114 *\end{array}$

'(.028) '(.067) '(.051) '(.054)

$\begin{array}{llll}.082 * * & .126 * * & 0.054 & 0.092\end{array}$

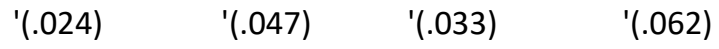

$\begin{array}{llll}.148 * * & 0.14 & 0.084 & .209 * *\end{array}$

'(.043) '(.101) '(.067) '(.075)

$\begin{array}{llll}0.001 & 0.158 & 0.064 & -.323^{* *}\end{array}$

$\begin{array}{llll} & 1.081) & 1\end{array}$

$\begin{array}{lll}.036+ & -0.011 & 0.042 \quad .065^{*}\end{array}$

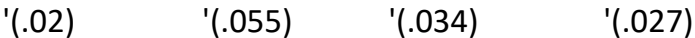

$.042+\quad 0.023 \quad 0.054 \quad .08+$

'(.022) '(.047) '(.034) '(.043)

$N$ (person-days) $\quad 16,961 \quad 3,615 \quad 3,253 \quad 7,916$

Fixed effects (person-centered) regressions; all regressions include an indicator for weekend days and whether the parent worked on that day. Standard errors clustered on family in parentheses. 
Figure 1. School/care disruptions by date

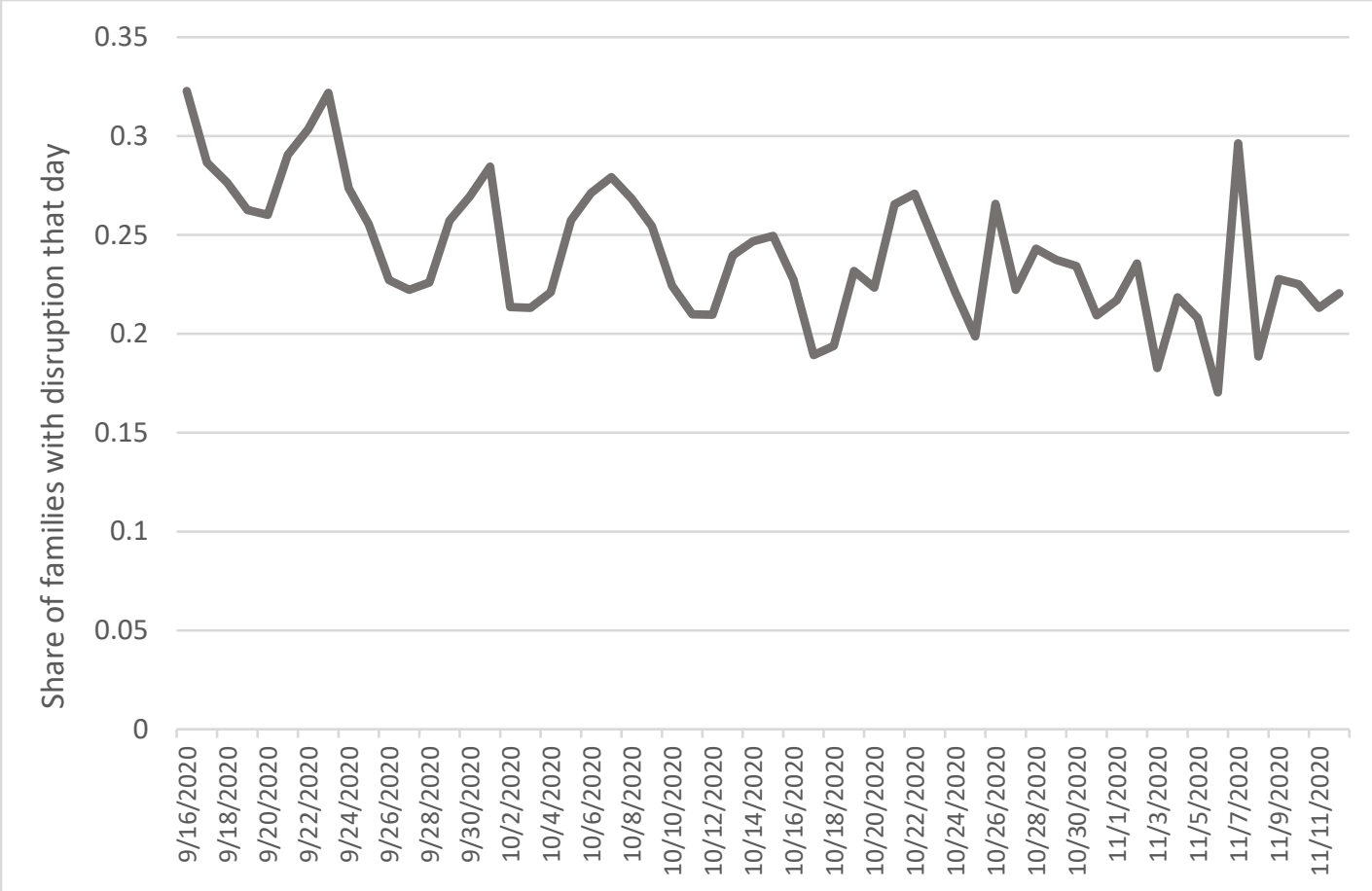


Effects of daily school and care disruptions on child mental health - 43

Figure 2. Daily effects of school/care disruptions on child behavior problems, parent mood and parenting behaviors

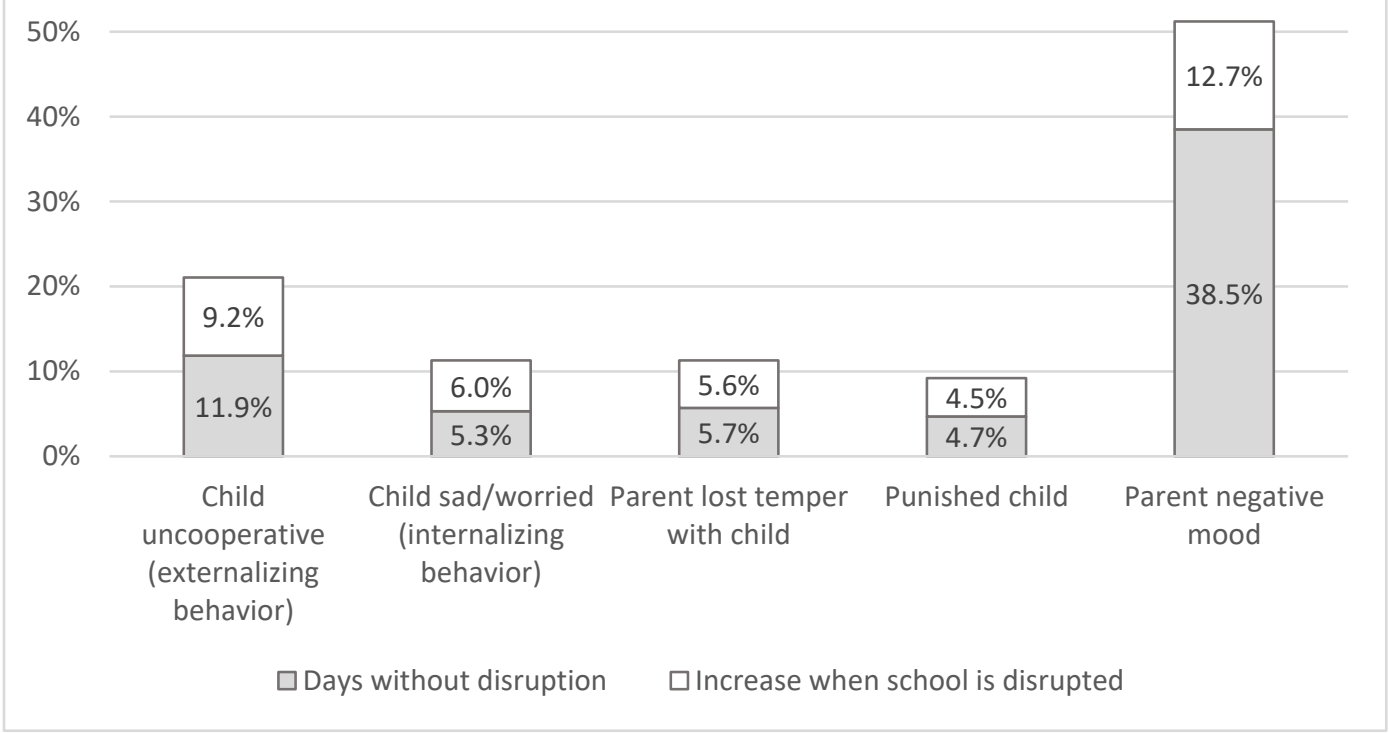

